DOI: 10.20472/IAC.2019.047.022

\title{
WUTHIYA SARAITHONG
}

Kasetsart University, Thailand

\section{KANOKWAN CHANCHAROENCHAI}

Kasetsart University, Thailand

\section{EXPLAINING THE ECONOMIC GROWTH OF THAILAND}

\begin{abstract}
:
One of the principles of economic development is economic growth. To ensure the sustainability, factors promoting long-term economic growth need to be analyzed. Understanding these factors could provide insightful information and, then, allow the government to properly plan for the future economic stimulating scheme. This study, therefore, looks into the determinants of economic growth in Thailand. The ARMA and ARCH techniques are employed to elicit significant factors and their impact on the country's economic growth between the first quarter of 2005 to the fourth quarter of 2017. The rate of change of GDP is applied as an indicator for economic growth. The result presents the volatile behavior or a sign of time-varying variance. Moreover, the finding preliminarily hypothesizes autoregressive characteristic. Technically, time-varying variance could be captured by $\mathrm{ARCH}$, while that of autoregressive could be taken into account by the ARMA. This study employs the inflation uncertainty to reflect the role of the internal instability on economic growth, and the exchange rate uncertainty to indicate the external instability. The $\operatorname{AR}(1)-\mathrm{GARCH}(0,1)$ model is appropriately estimated the inflation and its residual is taken as its uncertainty. On the other hand, the naive OLS-GARCH $(1,1)$ is the most suitable model to estimate the value of Thai baht and the unobserved portion is treated as its uncertainty. Finally, the economic growth is thus explored under the growth model framework with the Cobb-Douglas production form. The empirical results show that $A R(|2|)$ equation appears to be the most suitable model compared to others. These findings suggest that the government should implement promotion measures to attract foreign direct investment. In addition, labor productivity issue should be taken care of by the adjustment in education curriculum and on-the-job training.
\end{abstract}

\section{Keywords:}

$\mathrm{ARCH}, \mathrm{Cobb}-$ Douglas production, economic growth, uncertainty

JEL Classification: 000, 010 